\title{
Fatores determinantes na variação dos preços dos produtos contratados por pregão eletrônico*
}

\author{
Evandro Rodrigues de Faria** \\ Marco Aurélio Marques Ferreira*** \\ Lucas Maia dos Santos**** \\ Suely de Fátima Ramos Silveira*****
}

SumÁrio: 1. Introdução. 2. Referencial teórico. 3. Metodologia. 4. Resultados e discussão. 5. Conclusão.

Summary: 1. Introduction. 2. Theoretical benchmark. 3. Methodology. 4. Results and discussion. 5. Conclusion.

Palavras-chave: Pregão eletrônico; compras públicas; nova economia institucional.

KEY WORDs: Electronic bidding; public purchases; auctions theory.

A pesquisa buscou avaliar quais os fatores determinantes na variação dos preços dos produtos comprados através de pregão eletrônico. Para atingir os objetivos, testou-se a relação da variação dos preços com as variáveis: número de fornecedores, especificidade dos ativos, frequência das transações, quantidade, oportunismo dos agentes, tempo de existência e faturamento da empresa ganhadora e número de lances da disputa. Foram realizadas correlação de Pearson e regressão linear múltipla, com o

\footnotetext{
* Artigo recebido em nov. 2009 e aceito em jun. 2010.

** Mestre em administração pela Universidade Federal de Viçosa (UFV). Administrador. Endereço: Av. P. H. Rolfs, Campus Universitário, Departamento de Administração — CEP 36570-000, Viçosa, MG, Brasil. E-mail: evandro_farias@yahoo.com.br.

*** Doutor em economia aplicada pela UFV. Professor adjunto do Departamento de Administração da UFV. Endereço: Av. P. H. Rolfs, Campus Universitário, Departamento de Administração — CEP 36570-000, Viçosa, MG, Brasil. E-mail: marcoaurelio@ufv.br.

***** Graduando em administração pela UFV. Endereço: Av. P. H. Rolfs, Campus Universitário, Departamento de Administração - CEP 36570-000, Viçosa, MG, Brasil. E-mail: admlucasmaia@ hotmail.com.

$* * * * *$ Doutora em economia aplicada pela Escola Superior de Agricultura "Luiz de Queiroz" (Esalq/USP). Professora adjunta do Departamento de Administração da UFV. Endereço: Av. P. H. Rolfs, Campus Universitário, Departamento de Administração - CEP 36570-000, Viçosa, MG, Brasil.E-mail: sramos@ufv.br.
} 
intuito de explorar as relações entre as variáveis e construir um modelo para medir a variação dos preços. As variáveis número de fornecedores, especificidade dos ativos, quantidade e frequência das transações apresentaram um poder de explicação conjunta de $67,4 \%$ das variações dos preços. Assim, os órgãos públicos devem desenvolver ações que busquem maximizar o efeito destas variáveis com o objetivo de reduzir os preços pagos.

Determinative factors in the price variation of the products transacted by means of electronic reverse auction bidding

The research was intended to evaluate which were the determinative factors in the price variation of the products bought through electronic reverse auction bidding in the UFV ( Universidade Federal de Viçosa ). To reach the aims, the relation of the price variation and the following variables were tested: number of suppliers, specificity of the assets, transaction frequency, amount purchased, opportunism of the agents, time of existence and invoicing of the winner company, and the bids amount in the dispute. Pearson Correlation and Multiple Linear Regression were carried through with the intention to explore the relations between the variables and to construct a model to measure the prices variation. The results demonstrated that the number of suppliers, the specificity of the assets, the bought amount and the frequency of the transactions had a combined explanation influence on $67.4 \%$ of the variations of the prices practiced in biddings. As a result, the public agencies must develop actions that search to maximize the effect of these variables in the dispute, in order to obtain, in this way, greater economic profits through the reduction of the prices paid in their bidding processes.

\section{Introdução}

Em qualquer organização, o setor de compras constitui um componente importante para o alcance dos objetivos institucionais. Segundo Nunes et al. (2007), é por meio de uma eficiente aquisição de bens e serviços que uma organização conseguirá atingir seus fins com menos dispêndio de recursos financeiros e a satisfação dos seus stakeholders.

Para Batista e Maldonado (2008), existe um paralelismo grande entre a compra pública e a privada, pois ambas buscam o menor preço, com garantia de qualidade. Todavia, a compra pública requer procedimentos específicos para lhe dar eficácia, como a legislação; já na compra privada esses procedimentos são de livre escolha.

Em organizações públicas, o foco é a transparência das relações e o emprego dos recursos para a satisfação da sociedade. Assim, percebe-se que na governabilidade de um país deverão ser preservados valores que garan- 
tam a eficiência e a eficácia na utilização dos bens públicos da sociedade. Para isso, a administração pública vê-se obrigada a utilizar um alto grau de formalismo nas suas relações para aquisições de bens e contratações de serviços.

O objetivo da redução de custos e a agilização de rotinas e procedimentos nas compras e contratações têm sido uma prioridade na administração federal brasileira. A introdução de novos instrumentos, proporcionados pelas tecnologias da informática, ao lado da revisão da legislação e das normas, já experimentou avanços significativos (Pinto, 2002). Após a implantação do pregão eletrônico, foram abertas possibilidades inéditas de maior transparência, ampliação de oportunidades de participação e de competição e disseminação de mecanismos de controle gerenciais.

Segundo estudos de Compras Net (2005), o pregão eletrônico brasileiro possibilitou que, no ano de 2004, a administração direta gastasse, em compras de material de consumo e contratação de obras e serviços, $21 \%$ a mais do que no ano anterior. Concomitantemente, o número de empresas fornecedoras passou de 150 mil para 214 mil, o que representa um aumento de $42 \%$.

Para alguns autores, a exemplo de Vasconcellos (2008), o pregão eletrônico é a modalidade de licitação que apresenta o maior conjunto de pontos positivos para a administração pública, dos quais merecem destaque o aumento significativo no número de fornecedores e, consequentemente, a maior redução nos preços.

Embora tenham ocorrido avanços com a implementação do pregão eletrônico nas compras públicas, é consensual que ainda existe muito para se avançar com relação a avaliações e melhorias do sistema. Visando contribuir para o desenvolvimento, esse trabalho se propõe a responder a questão: quais fatores explicam o ganho econômico por parte da modalidade de licitação por pregão eletrônico?

A teoria microeconômica sobre estrutura de mercado e leilões mostra que um número maior de concorrentes proporciona, em geral, menor preço para os compradores. Neste trabalho, procura-se testar a hipótese de que com o aumento do número de ofertantes, através do pregão eletrônico, a instituição realiza suas compras pagando um preço menor do que o faria em outras modalidades de compra. Também verificam-se outras possíveis variáveis determinantes para que o preço final de um pregão eletrônico seja inferior ao preço estimado pela administração pública. 


\section{Referencial teórico}

\subsection{Teoria dos leilões}

A literatura sobre leilões demonstra, através de modelos teóricos propostos, que o número de participantes dos leilões afeta, significativamente, a receita dos leilões. Dessa forma, admitindo-se maior competição entre os participantes do mercado (traduzindo-se em um maior número de licitantes), haveria concorrência mais acirrada pelo objeto leiloado, obstando, assim, posições monopolísticas, que tendem a promover a concentração do mercado e a elevar as taxas praticadas nos leilões (Silva e Ferreira, 2007).

Assim, aumentando-se o número de licitantes, aumenta, concomitantemente, a probabilidade de que um licitante com maiores avaliações participe dos leilões e, desta forma, maior número de licitantes produziria, provavelmente, maiores ganhos para o leiloeiro. Contudo, um maior número de licitantes também reforça a praga do vencedor, pois em leilões com maior número de licitantes o lance ganhador provavelmente se afasta do consenso de mercado, fato este que, em geral, não é observado quando há poucos licitantes (Silva e Ferreira, 2007).

Vários autores têm discutido o efeito do número de fornecedores no preço pago. Para Carter (2007), existem várias evidências na literatura que colaboram com a ideia de que o número de licitantes é relacionado positivamente ao preço praticado em um leilão; porém ele acredita que esta relação não seja linear. Cox et al. (1982) perceberam que os preços de oferta eram significativamente mais altos em leilões com quatro, cinco, seis, e nove participantes que em leilões com três participantes. Dyer et al. (1989) compararam tamanhos de mercado de três e seis licitantes, e encontraram ofertas mais competitivas no segundo. Cox et al. (1988) não observaram nenhuma diferença significante nos preços de oferta quando existiam quatro, cinco, ou seis licitantes, porém no caso de três licitantes os preços eram significativamente maiores.

Os autores ressaltam ainda que, usualmente, o número de licitantes é tomado como exógeno com respeito ao formato do leilão e, nesse sentido, há poucas informações sobre os incentivos necessários à participação adequada dos licitantes nos diferentes formatos de leilão.

Wolfstetter (1999) afirma que a eficiência do leilão dependerá da existência de mecanismos e regras específicas que aumentem sua atratividade e reduzam as possibilidades de conluio, competição predatória e outras formas de poder de mercado. 
No tocante às propriedades principais dos leilões, é necessário registrar que, em condições bastante razoáveis (sinais dos valores dos compradores provêm da mesma função de distribuição de probabilidades), qualquer leilão padrão resulta na venda do objeto para o comprador com o maior sinal. Em outras palavras, os mecanismos de leilão geralmente resultam na aquisição do objeto por aquele indivíduo que mais atribui valor a ele ou que é mais eficiente (caso de empresas ou concessões, por exemplo), e usualmente os que atribuem maior valor ao objeto ou os mais eficientes são aqueles que estão dispostos a fazer lances maiores, resultando em uma receita maior da venda do objeto (Silva e Ferreira, 2007).

Durães (1997) afirma que a análise teórica, comparando os leilões com base na receita esperada, eficiência alocativa, custo de preparação dos lances e vulnerabilidade a fraudes, representa, basicamente, o cerne da teoria. Observa-se que o "leilão ótimo", capaz de maximizar a receita, ainda não foi satisfatoriamente desenvolvido na teoria dos leilões. Há de se ressaltar também, que no caso da administração pública a orientação de maximização se inverte para o menor custo, dados os padrões, qualidade e condicionalidades exigidos.

Assim, não há uma tipologia para leilões que seja universalmente aceita. Em verdade existem inúmeras formas híbridas que são derivações de tipos clássicos que, em sua grande maioria, têm reduzida importância no que tange aos seus aspectos práticos e teóricos.

De acordo com Klemperer (2004), existem quatro formatos clássicos de leilão, que serviriam de base para os desenhos efetivamente utilizados nos diferentes mercados: 1. leilão fechado de primeiro preço; 2 . leilão fechado de segundo preço (ou leilão de Vickrey); 3. leilão ascendente (também conhecido por leilão aberto, oral, ou inglês); e 4. leilão descendente (também chamado de holandês).

O mecanismo de leilões tem sido largamente utilizado em atividades de comércio eletrônico na internet, sobretudo nos mercados C2C (consumer to consumer) e B2C (businesses to consumers). Tal asserção pode ser comprovada pelo volume crescente de transações efetuadas sobre os mais variados bens e serviços, desde commodities, como no caso de produtos agrícolas, até obras de arte, produtos eletrônicos e passagens aéreas (Klein, 1997). Com regras simples e bem definidas, os leilões promovem maior flexibilidade à tarefa de determinação de preços, que até então eram fixos, definidos unilateralmente pelo vendedor, não cabendo espaço para negociação entre as partes, configurando uma situação do tipo "pegar ou largar", na qual os compradores se viam impedidos de fazer contrapropostas. Recentemente, observa-se um interesse crescente de organizações e governos na utilização da modalidade de leilões eletrônicos reversos em seus processos aquisitivos (Menezes et al., 2007). 


\subsection{Nova Economia Institucional}

A Nova Economia Institucional (NEI) comporta em sua origem uma crítica a determinados pressupostos da ortodoxia neoclássica, particularmente em suas proposições de individualismo metodológico, de racionalidade ilimitada dos agentes econômicos e de existência de informação completa e homogeneamente acessível (Valle e Filho, 2001).

Buscando a elaboração de uma abordagem mais próxima à realidade, os teóricos da NEI observaram que as instituições não poderiam ser negligenciadas no estudo do ambiente econômico, dada sua grande influência não apenas sobre os custos de seu funcionamento (custos de transação), mas também sobre a própria tecnologia (North, 1994).

A Economia de Custos de Transação (ECT) ganhou força através dos estudos de Williansom (1985). A ECT foi construída com base em alguns pressupostos. O pressuposto básico é a existência de custos nas transações em si. Ou seja, além do preço do produto ou serviço final, envolvem-se também os custos para transacionar este produto ou serviço, levando-se em conta não só os custos gerados pelos contratos feitos via mercado, mas também os coordenados pelas firmas (Lucci, 2004).

Outro pressuposto diz respeito às características dos agentes econômicos. Os agentes têm racionalidade limitada e são capazes de comportamento oportunista. Especificidade dos ativos unida à racionalidade limitada, oportunismo e incerteza causam tensão contratual e organizacional. Este aspecto foi abordado por Williamson et al. (1990), que desenvolveram um modelo a partir da incorporação dos chamados "atributos das transações" e dos "pressupostos comportamentais" ao conceito de custos de transação. Em linhas gerais, afirma-se que tais custos decorrem destes dois condicionantes. Os pressupostos comportamentais são a racionalidade limitada e o oportunismo. Por sua vez, os principais atributos de uma transação são o grau de especificidade do ativo, a frequência e a incerteza, sendo a especificidade o atributo mais relevante na determinação dos custos de transação.

\section{Racionalidade limitada}

Ao realizar um contrato, os indivíduos tentam se assegurar, prevendo todos os cenários e eventualidades possíveis. No entanto, é impossível saber ao certo tudo o que pode acontecer. Para Júnior e Machado (2003), os agentes 
econômicos procuram agir racionalmente no momento em que tomam uma determinada decisão. No entanto, possuem uma limitação cognitiva que os impede de antever algo que possa acontecer no futuro. A racionalidade limitada deriva da conviç̧ão de que os agentes econômicos, embora tentem pautar suas ações em moldes estritamente racionais, só conseguem fazê-lo de modo parcial, dada a assimetria informacional e a restrita capacidade de processamento das informações. (Valle e Filho, 2001).

Ao assumir como verdadeiro o pressuposto da racionalidade limitada do ser humano, a qualidade das informações passa verdadeiramente a ser uma variável chave para a tomada de decisões, sendo esta, talvez, uma das grandes contribuições teóricas da Nova Economia Institucional.

\section{Oportunismo}

Oportunismo é o outro pressuposto comportamental, sendo um conceito que resulta da ação dos indivíduos na busca do seu autointeresse. Para Alves e Staduto (1999), dada a oportunidade, o tomador de decisão pode, inescrupulosamente, procurar atender seus próprios interesses, e há a dificuldade de conhecer "a priori" quem é de confiança e quem não é, podendo ser definido como problema de assimetria informacional. Williamson (1985) definiu oportunismo como "procurar seus próprios interesses com avidez", incluindo comportamentos como mentira e trapaça, e também as mais sutis formas de enganar, tal como violação de contrato. Depreende-se, então, que o oportunismo está vinculado à noção de que os agentes econômicos buscarão sempre obter o maior ganho possível no decorrer das transações, ainda que isso implique perdas aos demais (Valle et al., 2002).

No caso das licitações, os participantes poderão agir com oportunismo quando órgãos públicos não especificarem de forma completa o produto licitado. Assim, os fornecedores poderão se aproveitar desta incompletude para cotar produtos de pior qualidade ou que não atendam as necessidades do comprador.

\section{Frequência}

A frequência é uma medida da recorrência com que uma transação se efetiva. Seu papel é duplo. Primeiro, quanto maior a frequência, menores serão os custos fixos médios associados à coleta de informações e à elaboração de um contrato complexo que imponha restrições ao comportamento oportunista. 
Segundo, se a frequência for muito elevada, os agentes terão motivos para não impor perdas aos seus parceiros, na medida em que uma atitude oportunista poderia implicar a interrupção da transação e a consequente perda dos ganhos futuros derivados da troca (Souza et al., 1998).

A teoria aponta que uma maior frequência nas transações entre os mesmos agentes gera o que se chama de "reputação". O detalhe é que a reputação tende a reduzir os custos de transação, tendo em vista não haver a necessidade de se buscar informações acerca do parceiro comercial e da qualidade do produto transacionado. Portanto, segundo a ECT, quanto maior a frequência nas transações, maior o nível de reputação e consequentemente menores os custos de transação envolvidos (Arbage, 2004).

\section{Incerteza}

Segundo Santos (2001), a incerteza consiste na incapacidade dos agentes de prever e estabelecer cláusulas que assegurem a performance dos agentes quando há ocorrência de eventos não previsíveis. Ou seja, a incerteza não é redutível ao risco. Quanto mais incerto é o ambiente, mais ineficientes serão as adaptações descentralizadas, gerando, portanto, maior instabilidade para as transações.

A incerteza está associada à impossibilidade de os agentes preverem algo que possa acontecer e colocar em risco a transação como, por exemplo, as variações climáticas. Esta situação faz com que haja um prazo maior para que as partes renegociem um novo contrato (Júnior e Machado, 2003).

No campo organizacional, a fonte fundamental de incerteza decorre exatamente do suposto de racionalidade limitada dos agentes. Não fosse esse aspecto, as estruturas de governança seriam capazes de se ajustar às alterações havidas no ambiente. Para muitos autores este é o grande problema das organizações econômicas: a constante necessidade de adaptação às alterações de natureza institucional que ocorrem no ambiente dos negócios (Arbage, 2004).

\section{Especificidade dos ativos}

A especificidade dos ativos é introduzida por Williamson (1985) para designar a perda de valor dos investimentos no caso de quebras oportunísticas dos contratos (Zylbersztajn, 2002). Um ativo é especifico quando a sua realocação para outra atividade, no caso de um rompimento no contrato, por exemplo, é 
praticamente inexistente. A especificidade de ativos coloca em risco o investimento feito, caso a transação não seja realizada pelo fato de o uso alternativo desse investimento ser baixo ou não existir (Júnior e Machado, 2003). Segundo Souza et al. (1998), ativos são específicos se o retorno associado a eles depende da continuidade de uma transação específica. Quanto maior a especificidade dos ativos, maior a perda associada a uma ação oportunista por parte de outro agente. Consequentemente, maiores serão os custos de transação.

Com a presença de especificidade dos ativos, os agentes envolvidos na transação passam a ter um relacionamento semelhante ao de um monopólio bilateral, no qual ambas as partes possuem um determinado poder de barganha e se utilizam dele a fim de buscar para si maior participação na "renda" gerada por este ativo específico (Pinto Júnior e Pires, 2000).

No entanto, o rompimento do contrato pode não ser interessante quando a alta especificidade está muito mais definida para uma das partes. Nesse caso, a parte mais afetada se salvaguardará de uma eventual ruptura contratual pela parte não afetada. Outra situação acontece quando todos os envolvidos fazem investimentos específicos, ou seja, no caso de dependência bilateral. Assim acontecendo, os esforços serão concentrados para que o contrato continue indefinidamente (Diniz et al., 2004).

\section{Metodologia}

Segundo Vergara (2005), existem diversas taxonomias de tipos de pesquisa que variam conforme os critérios utilizados na categorização. Essa autora sugere duas formas de classificação: quanto aos fins e quanto aos meios. De maneira semelhante, Gil (2002) apresenta dois critérios de classificação, sendo um baseado nos objetivos gerais do estudo, e o outro, com base nos procedimentos técnicos adotados.

Assim, de acordo com a classificação sugerida por Vergara (2005), quanto aos fins, esta pesquisa caracteriza-se como descritiva, uma vez que se pretende descrever e analisar os fatores determinantes na variação de preços praticados em pregões eletrônicos.

Segundo Vergara (2005), as pesquisas descritivas têm como objetivo a descrição das características de determinada população ou fenômeno, podendo ainda estabelecer correlações entre variáveis e definir sua natureza.

Quanto aos meios de investigação para este trabalho, foram utilizadas as análises bibliográfica e documental. A pesquisa bibliográfica foi empregada na definição dos conceitos utilizados no estudo, bem como na consulta a ou- 
tros estudos sobre pregões eletrônicos e teoria dos leilões. Para tal, foram feitas consultas a livros, teses, dissertações, artigos científicos e demais materiais disponíveis ao público em geral. Vergara (2005) define pesquisa bibliográfica como o estudo sistematizado desenvolvido com base em material publicado.

A pesquisa documental foi realizada na base de dados do Sistema Integrado de Administração de Serviços Gerais (Siasg) do governo federal, onde foram coletados os dados referentes aos processos licitatórios da Universidade Federal de Viçosa (UFV), localizada na cidade de Viçosa, estado de Minas Gerais, Brasil. A investigação documental, segundo Gil (2002), assemelhase muito à bibliográfica; contudo, ao contrário desta, a pesquisa documental baseia-se em materiais que ainda não sofreram tratamento analítico, ou que ainda podem ser reorganizados de acordo com os propósitos do estudo.

A investigação foi também documental, pois foram utilizados documentos eletrônicos da UFV, como atas de pregões, processos de licitação e outros documentos pertinentes com o objeto do estudo. Segundo Vergara (2005), "a investigação documental é realizada em documentos conservados em órgãos públicos e privados de qualquer natureza".

\subsection{Estratégia de coleta de dados}

Para a coleta de dados foram utilizadas duas estratégias. A primeira foi acessar a base de dados do Siasg e do ComprasNet para a coleta de dados secundários referentes à disputa das licitações e às empresas vencedoras.

Outra fonte foi primária, decorrente da aplicação de questionários às empresas vencedoras de leilões para contratação de produtos no período entre setembro e dezembro de 2008. Das 195 empresas vencedoras no período estudado, 75 responderam o questionário, mas apenas 59 foram utilizados para a composição do modelo, devido a problemas como ausência de informações pertinentes e questionários outliers.

O questionário utilizado foi composto por perguntas correspondentes às características da empresa e outras questões do tipo escala Likert para a elaboração dos escores de oportunismo, frequência e especificidade dos ativos de acordo com os princípios da ECT.

\subsection{Análise e tratamento dos dados}

Para alcançar o objetivo geral da pesquisa, que é construir um modelo quantitativo para explicar a redução dos custos de licitações pelo pregão eletrôni- 
co, foi escolhida uma abordagem metodológica de natureza quantitativa, pois serão adotadas variáveis quantificáveis. De acordo com Bruyne et al. (1991), a quantificação estabelece uma correspondência entre as dimensões de cada conceito e números dispostos segundo determinadas regras; autoriza a comparabilidade numérica e a aplicação de métodos de tratamento quantitativo.

Para quantificar a influência das variáveis preditoras na variação dos preços dos fornecedores do órgão público estudado foram realizadas análises multivariadas, utilizando o software Statistical package for the social science (SPSS versão 15.0), com destaque para as análises de correlação e de regressão linear múltipla. Outros trabalhos sobre a teoria dos leilões também utilizaram estas análises, a exemplo de Resnick e Zeckhauser (2002), Brülhart e Trionfetti (2004), Harstad (2005), Shawn e Nath (2005), Hyytinen (2006), Lösch (2006), Engelbrecht-Wiggans e Katok (2007) e Teo et al. (2008).

\subsection{Modelo estatístico}

No propósito de explicar a variação dos preços praticados em pregões eletrônicos foram testadas algumas variáveis, cujas expectativas teóricas estão descritas na Tabela 1.

\section{Tabela 1 \\ Descrição das variáveis do modelo}

\begin{tabular}{|c|c|c|}
\hline Variável & Descrição & Sinal esperado do coeficiente \\
\hline$Y_{n}$ & $\begin{array}{l}\text { Variável a ser explicada pelo modelo. } \\
\text { Ela corresponde à variação percentual } \\
\text { que o pregão eletrônico proporcionou } \\
\text { ao preço de venda do produto. O seu } \\
\text { cálculo se deu pela diferença entre o } \\
\text { preço praticado na empresa ganhadora } \\
\left(p_{v}\right) \text { e o preço praticado na licitação }\left(p_{p}\right) \\
\text { sobre o }\left(p_{v}\right) \text {, conforme equação a seguir: } \\
Y_{n}=\left(p_{v}-p_{\nu}\right) /\left(p_{v}\right) \\
\text { Esta variável reflete o ganho ou perda que } \\
\text { o órgão público teve ao comprar através } \\
\text { desta modalidade de licitação. }\end{array}$ & Sem interpretação do sinal. \\
\hline Forn $_{n}$ & $\begin{array}{l}\text { Número de fornecedores que competi- } \\
\text { ram pelo item } n \text { de um pregão. }\end{array}$ & $\begin{array}{l}\text { Positivo, pois parte-se da teoria dos leilões } \\
\text { que afirma que com o aumento do número } \\
\text { de concorrentes, o leiloeiro consegue maiores } \\
\text { ganhos. }\end{array}$ \\
\hline
\end{tabular}




\begin{tabular}{|c|c|c|}
\hline Variável & Descrição & Sinal esperado do coeficiente \\
\hline Lanc $_{n}$ & $\begin{array}{l}\text { Número de lances dados na disputa do } \\
\text { item } n \text { de um pregão. }\end{array}$ & $\begin{array}{l}\text { Positivo, pois o lance é uma redução gradativa } \\
\text { dos preços, por isso sugere-se que quanto } \\
\text { mais lances são realizados, maior a redução } \\
\text { final. }\end{array}$ \\
\hline Quant $_{n}$ & $\begin{array}{l}\text { Quantidade comprada do item } n \text { de } \\
\text { um pregão. }\end{array}$ & $\begin{array}{l}\text { Positivo, pois quando vende maiores quanti- } \\
\text { dades de um produto, a empresa pode abrir } \\
\text { mão de uma margem maior. }\end{array}$ \\
\hline Fat $_{n}$ & $\begin{array}{l}\text { Faturamento da empresa vencedora na } \\
\text { disputa do item } n \text { de um pregão. }\end{array}$ & $\begin{array}{l}\text { Positivo, pois julga-se que empresas de maior } \\
\text { porte conseguem ser mais eficientes e organi- } \\
\text { zadas e, assim, têm condições de apresentar } \\
\text { um preço menor. }\end{array}$ \\
\hline Exist $_{n}$ & $\begin{array}{l}\text { Tempo de existência, em anos, da empre- } \\
\text { sa vencedora do item } n \text { de um pregão. }\end{array}$ & $\begin{array}{l}\text { Positivo, pois presume-se que empresas com } \\
\text { maior tempo de existência possuem maior } \\
\text { eficiência e, assim, conseguem praticar preços } \\
\text { menores. }\end{array}$ \\
\hline Especif $_{n}$ & $\begin{array}{l}\text { Escore de especificidade dos ativos da } \\
\text { empresa vencedora do item } n \text { de um } \\
\text { pregão. }\end{array}$ & $\begin{array}{l}\text { Negativo, pois quanto maior a especificidade } \\
\text { do produto comprado, menor será o número } \\
\text { de empresas concorrentes e por isso menor } \\
\text { será a concorrência da licitação. }\end{array}$ \\
\hline Oportun $_{n}$ & $\begin{array}{l}\text { Escore de oportunismo da empresa ven- } \\
\text { cedora do item } n \text { de um pregão. }\end{array}$ & $\begin{array}{l}\text { Negativo, pois empresas oportunistas buscam } \\
\text { maiores ganhos individuais e, assim, a redução } \\
\text { será menor à medida que cresce o grau de } \\
\text { oportunismo. }\end{array}$ \\
\hline Freq $_{n}$ & $\begin{array}{l}\text { Escore de frequência da empresa vence- } \\
\text { dora do item } n \text { de um pregão. }\end{array}$ & $\begin{array}{l}\text { Positivo, pois fornecedores que prezam rela- } \\
\text { cionamentos mais duradouros fazem maiores } \\
\text { esforços para continuar o fornecimento e para } \\
\text { isso são obrigados a reduzir seus preços. }\end{array}$ \\
\hline
\end{tabular}

Fonte: Resultados de pesquisa

O modelo foi estimado pelo método dos mínimos quadrados ordinários (MQO). Segundo Corrar et al. (2007), seu objetivo é obter a menor soma de quadrados dos resíduos possível. Para ele, a equação que melhor se ajusta aos dados é aquela para a qual a diferença entre os valores estimados é menor.

O modelo buscará seguir a seguinte equação:

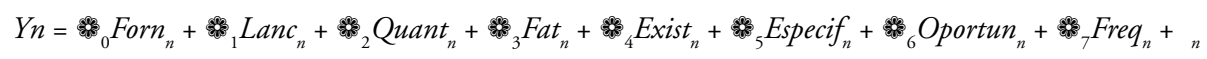

Esse modelo se assemelha ao apresentado por Silva e Ferreira (2007), que propuseram um modelo onde a variável explicada seria a diferença entre 
o valor estimado pelo gestor público, contido no edital do processo licitatório, e o menor lance. Porém, aquele valor possui um viés científico, pois na prática as pessoas responsáveis pela estimativa dos bens a serem comprados não utilizam critérios para o levantamento deste valor, sendo muitas vezes utilizados dados de licitações passadas, o que deixa estes valores desatualizados, sem refletir a lógica dos preços do mercado.

Assim, uma abordagem que utilize os preços da marca vencedora da disputa, cotados diretamente na empresa com menor preço na licitação, mostrará se o processo licitatório levou a empresa a vender por um preço abaixo do praticado ou se ele possibilitou que ela vendesse obtendo um ágio na transação.

\section{Resultados e discussão}

Para a análise da confiabilidade dos constructos de especificidade dos ativos, oportunismo e frequência, foi calculado o Alfa de Cronbach. De acordo com Hair et al. (2005) ele é capaz de revelar o grau em que os itens de um instrumento são homogêneos e refletem um determinado constructo implícito. O coeficiente Alfa de Cronbach varia entre 0,00 e 1,00, sendo os valores de 0,60 a 0,70 considerados o limite inferior de aceitabilidade.

Após a análise dos resultados verifica-se, na Tabela 2, que os valores estão acima do limite inferior de aceitabilidade, o que evidencia a existência de confiabilidade na mensuração dos princípios estabelecidos.

Tabela 2

Validação dos constructos propostos na pesquisa

\begin{tabular}{|c|c|c|}
\hline Constructo & Variáveis & $\begin{array}{l}\text { Alfa de } \\
\text { Cronbach }\end{array}$ \\
\hline $\begin{array}{l}\text { Especificidade } \\
\text { dos ativos }\end{array}$ & $\begin{array}{l}\text { Intensidade de concorrência } \\
\text { Poucos fabricantes do produto vendido } \\
\text { Ocorrência de licitações desertas } \\
\text { Pequeno número de participantes em pregões eletrônicos }\end{array}$ & 0,732 \\
\hline Oportunismo & $\begin{array}{l}\text { Cotação de produtos de má qualidade } \\
\text { Oportunismo em editais com especificações incompletas } \\
\text { Cotação de produtos fora das especificações do edital } \\
\text { Oportunismo em regiões distantes para compensar custos }\end{array}$ & 0,752 \\
\hline Frequência & $\begin{array}{l}\text { Políticas de preços mais favoráveis a órgãos públicos conhecidos } \\
\text { Políticas de qualidade mais favoráveis a órgãos públicos conhecidos } \\
\text { Esforço para vencer disputas de orgãos públicos conhecidos } \\
\text { Esforço para cumprimento das normas }\end{array}$ & 0,704 \\
\hline
\end{tabular}

RAP - RIO DE JANEIRO 44(6): 1405-28, NOV./DEZ. 2010 
Fonte: Resultados de pesquisa

Para verificar a existência de relação linear entre as variáveis utilizadas e a redução trazida pelo pregão eletrônico, primariamente foi realizado teste de correlação simples de Pearson.

Ao analisar os resultados, presentes na Tabela 3, verifica-se que, das oito variáveis estudadas, apenas duas variáveis não possuem correlações significantes a $10 \%$, sendo cinco delas significantes a $5 \%$. As variáveis que possuem maior intensidade de relação são, respectivamente, o número de fornecedores, especificidade dos ativos e número de lances.

\section{Tabela 3 :}

\section{Correlação de Pearson entre as variáveis preditoras e a variável explicada}

\begin{tabular}{|lrrrrrrrc|}
\hline & Freq $_{n}$ & Forn $_{n}$ & Lanc $_{n}$ & Quant $_{n}$ & Exist $_{n}$ & Fat $_{n}$ & Especif $_{n}$ & Oportun $_{n}$ \\
\hline Correlação & $47,7 \%$ & $70,4 \%$ & $56,3 \%$ & $31,2 \%$ & $-5,8 \%$ & $22,8 \%$ & $-62,4 \%$ & $8,3 \%$ \\
Significância & 0,000 & 0,000 & 0,000 & 0,016 & 0,663 & 0,082 & 0,000 & 0,534 \\
\hline
\end{tabular}

Fonte: Resultados de pesquisa

Para a construção do melhor modelo de regressão foi utilizado o método stepwise. Nesse sentido, Maroco (2003:420) afirma que os procedimentos de seleção de variáveis apresentam vantagem de indicar, com base num critério exato, quais as variáveis que apresentam relações mais fortes com a variável dependente e por isso são melhores candidatas ao modelo definitivo.

De acordo com a Tabela 4, observa-se que foram sugeridos quatro modelos através deste método, sendo o modelo 4 aquele com maior poder de explicação. As variáveis: número de fornecedores, especificidade dos ativos, frequência e quantidade obtiveram um grau de associação de 83,5\% com a variável variação dos preços praticados.

O coeficiente de determinação $\left(\mathrm{R}^{2}\right)$ de 0,696 mostra que $69,6 \%$ das variações no preço praticado em licitações são explicados pela variação conjunta das variáveis escolhidas pelo modelo.

Outra observação relevante é o maior valor do $\mathrm{R}^{2}$ ajustado. Segundo Corrar et al. (2007), quando a pretensão é a comparação entre várias equações de regressão, envolvendo número de variáveis independentes diferentes, o valor do $\mathrm{R}^{2}$ ajustado é mais indicado que o do $\mathrm{R}^{2}$. Desse modo, comparando os modelos estudados, vimos que o modelo 4 é o mais eficiente, pois apresenta coeficiente de determinação ajustado maior que os demais 
modelos.

Tabela 4

Modelos de regressão múltipla obtidos pelo método stepwise

\begin{tabular}{|llccc|}
\hline Modelo & Variáveis preditoras & $\mathrm{R}$ & $\mathrm{R}^{2}$ & $\mathrm{R}^{2}$ Ajustado \\
\hline 1 & Forn $_{n}$ & 0,704 & 0,496 & 0,487 \\
2 & Forn $_{n^{\prime}}$ Especif $_{n}$ & 0,797 & 0,635 & 0,622 \\
3 & Forn $_{n^{\prime}}$ Especif $_{n^{\prime}}$ Freq $_{n}$ & 0,820 & 0,672 & 0,654 \\
4 & Forn $_{n^{\prime}}$ Especif $_{n^{\prime}}$ Freq $_{n^{\prime}}$ Quant $_{n}$ & 0,835 & 0,696 & 0,674 \\
\hline
\end{tabular}

Fonte: Resultados de pesquisa

Os resultados obtidos através deste modelo são mais eficientes que o modelo proposto por Silva (2007), sendo o $\mathrm{R}^{2}$ ajustado do modelo proposto em seu trabalho de 17,6\%. Porém é pertinente ressaltar que a regressão apresentada por este autor testou apenas as variáveis número de fornecedores e número de lances. Outra diferença entre os modelos é a metodologia adotada para o cálculo da variável explicada $\mathbb{W}$, sendo aqui adotada a diferença percentual entre o preço de venda da empresa ganhadora e o preço praticado na licitação, e em Silva (2007) utilizada a diferença entre o valor estimado e o valor da licitação.

O poder explicativo do número de fornecedores corrobora as afirmações de Cottarelli (1995) e Durães (1997), que indicam que o número de participantes aumenta significativamente o ganho dos leiloeiros. Para eles, quanto maior o universo de interessados no leilão, menor é a chance de ações monopolísticas, o que diminui o valor pago pelo bem a ser comprado pelos órgãos públicos.

Confirmam-se também os trabalhos de Millet et al. (2004) e Ferro (2006), que encontraram relações positivas entre estas variáveis. Os resultados também contradizem Carter et al. (2004), quando estes afirmam que a relação entre o número de participantes e a redução pode não ser linear, o que foi refutado por esta pesquisa.

O poder de explicação da variável especificidade dos ativos está associado ao fato de que, segundo Peres (2007), com a presença de especificidade dos ativos, os agentes envolvidos na transação passam a ter um relacionamento semelhante ao de um monopólio, em que os agentes adquirem um maior poder de barganha e se utilizam disso para obter maiores ganhos. Desta maneira, quanto maior é a especificidade dos ativos, menor será a disponibilidade de um produto no mercado, maior será o preço praticado pelos agentes e menor 
será a redução proporcionada pelos processos licitatórios.

A inclusão da variável frequência pode ser explicada por Júnior (2003), ao afirmar que aumentando a frequência, os custos de transação tendem a baixar. Para Arbage (2004), quanto maior a frequência nas transações, maior o nível de reputação e consequentemente menores os custos de transação envolvidos. Este resultado se assemelha ao obtido por Reiley et al. (2007), que testaram o efeito da reputação do vendedor nos preços praticados em leilões.

Outro fator explicativo é a composição do escore frequência, pois as empresas com maior pontuação se mostraram mais interessadas em uma relação mais duradoura, e para isso criam políticas mais favoráveis de preços para órgãos públicos que lhes interessam para maior frequência de transações.

A entrada da variável quantidade no modelo pode ser explicada pelo fato de que quanto maior for a quantidade vendida, mais interessa à empresa abrir mão de margens de lucros maiores para obter vantagens através do volume de vendas. Ou seja, um claro trade off entre margem e giro, comum nos grandes negócios.

Esperava-se que as demais variáveis contribuíssem com o poder de explicação do modelo, contudo, não existem na teoria - com exceção da variável número de lances, que teve relação significativa no modelo de Silva e Ferreira (2007) e foi citada como importante para redução por Wenyan e Bolívar (2008) - afirmações que comprovem a relação destas variáveis com a redução dos preços em leilões reversos.

Uma das justificativas da não inclusão da variável número de lances é o fato de que em pregões eletrônicos, geralmente, não existe limite mínimo de lance, podendo este ser apenas alguns centavos abaixo da proposta anterior, o que não produz efeito significativo na redução percentual final do objeto licitado.

O oportunismo também foi citado no trabalho de Loesch (2007) como fator que poderia influenciar a variação dos preços praticados em leilões reversos; contudo, no modelo proposto neste trabalho não se obteve uma relação significativa.

Porém, para melhor validação dos resultados, é necessário analisar a validade dos pressupostos do modelo.

$\mathrm{O}$ primeiro passo é refutar a hipótese de $\mathrm{R}^{2}$ ser igual a zero. Utilizando o teste F-Anova, verifica-se na Tabela 5 que a significância é menor que $0,01 \%$, por isso rejeita-se a hipótese de que o coeficiente de determinação seja igual a zero. Assim, pelo menos uma das variáveis independentes exerce influência 
sobre a variação dos preços praticados.

Tabela 5

Teste Anova

\begin{tabular}{|llcc|}
\hline Modelo & & Soma dos quadrados & Significância ANOVA \\
\hline 1 & Regressão & 6066,12 & 0,000 \\
& Resíduos & 6166,68 & \\
\hline 2 & Regressão & 7766,88 & 0,000 \\
& Resíduos & 4465,92 & 0,000 \\
\hline 3 & Regressão & 8215,63 & \\
& Resíduos & 4017,17 & 0,000 \\
\hline
\end{tabular}

Fonte: Resultados de pesquisa

Na Tabela 6 pode-se verificar o coeficiente beta das variáveis presentes na construção do modelo de regressão múltipla. É importante ressaltar que através do teste $\mathrm{T}$ pode-se rejeitar, com nível de significância de $5 \%$, a hipótese de que os coeficientes são iguais a zero.

Tabela 6

Coeficientes dos fatores determinantes na variação dos preços dos pregões eletrônicos

\begin{tabular}{|lccc|}
\hline Variável & Coeficiente beta & Erro-padrão & Significância (t) \\
\hline Constante & 6,077 & & 0,186 \\
Forn $_{n}$ & 1,235 & 0,486 & 0,000 \\
Especif $_{n}$ & $-1,019$ & $-0,348$ & 0,000 \\
Freq $_{n}$ & 0,496 & 0,181 & 0,031 \\
Quant $_{n}$ & 0,017 & 0,163 & 0,040 \\
\hline
\end{tabular}

Fonte: Resultados de pesquisa

Dessa forma, foi possível obter a seguinte equação para previsão da variação dos preços praticados em licitações:

$$
Y_{n}=6,077+1,235 \text { Forn }_{n}-1,019 \text { Especif }_{n}+0,017 \text { Quant }+0,496 \text { Freq }_{n}
$$

Observa-se que, em média, o aumento de um fornecedor no pregão 
proporciona um ganho de $1,235 \%$ na redução dos preços. Esta relação é parecida com a encontrada no trabalho de Silva (2007), de 1,07\%. O resultado confirma a expectativa da teoria dos leilões, que afirma que o preço praticado em um leilão é fortemente influenciado pelo número de participantes.

O aumento de cada ponto do escore de especificidade dos ativos, proposto por esta pesquisa, está associado a 1,019\% das variações negativas dos preços praticados. Isto colabora com a ECT, que afirma que a especificidade dos ativos aumenta os custos das transações.

A variação de uma unidade da quantidade dos itens comprados está associada à variação de $0,017 \%$ da variável explicada pelo modelo. Isto pode ser esclarecido pelo fato de que quanto maior a quantidade comprada mais se diluem custos associados à transação, como frete e custos de postagem. Outra explicação seria a opção das empresas por maior giro em detrimento de maiores margens de lucro.

Cada ponto do escore de frequência está associado à variação de $0,496 \%$ na redução dos preços praticados. Assim, aqueles fornecedores que buscam uma maior frequência nas transações apresentam menores preços em licitações.

Porém é importante ressaltar que, segundo Corrar (2007), a análise multivariada requer testes de suposições para as variáveis separadas e em conjunto, e cada técnica apresenta seu conjunto de suposições e pressupostos. Os principais pressupostos para a regressão são: normalidade dos resíduos, homocedasticidade dos resíduos, e multicolinearidade entre as variáveis independentes.

Para testar a normalidade dos resíduos foi utilizado o teste KolmogorovSmirnov, que examina se determinada série está conforme a distribuição esperada. Conforme a Tabela 7 , não se rejeita a hipótese nula de que se trata de uma distribuição normal, cumprindo-se assim o pressuposto de normalidade.

Tabela 7

Pressuposto de normalidade da regressão

\begin{tabular}{|cc|}
\hline Kolmogorov-Smirnov & Significância \\
\hline 0,749 & 0,628 \\
\hline
\end{tabular}

Fonte: Resultados de pesquisa

Para testar se a variância dos resíduos mantém-se em todo o espectro das variáveis independentes, ou seja, examinar a existência de homocedasticidade dos resíduos, foi utilizado o teste Pesarán-Pesarán. Sua forma consiste 
em se regredir o quadrado dos resíduos padronizados em função do quadrado dos valores estimados padronizados. Caso o modelo apresente significância abaixo de 5\%, o modelo é considerado heterocedástico e por isso não apresenta comportamento aleatório em relação às variáveis independentes.

Após a aplicação do teste, pôde-se verificar que a significância apresentada foi de $36,3 \%$, o que indica a não rejeição da hipótese nula de existência de homocedasticidade.

Tabela 8

\section{Diagnóstico de homocedasticidade dos resíduos}

\begin{tabular}{|lcc|}
\hline & Soma dos quadrados & Significância Anova \\
\hline Regressão & 0,960 & 0,363 \\
Resíduos & 65,127 & \\
\hline
\end{tabular}

Fonte: Resultados de pesquisa

É importante também analisar o diagnóstico de colinearidade, que indica se há correlações entre as variáveis, sob pena de incorrer em problemas na estimação dos parâmetros do modelo. Segundo Hair et al. (2005), quando as variáveis são multicolineares, fornecem informações semelhantes para explicar e prever determinado fenômeno. O impacto da multicolinearidade é reduzir o poder preditivo de qualquer variável independente na medida em que ela é associada com as demais variáveis.

Com base na Tabela 9, percebe-se que o valor do tolerance é superior a 0,7, o que, segundo Hair et al. (2005), sugere a ausência de multicolinearidade; como o VIF é o oposto, valores abaixo de 1,3 também sugerem esta ausência.

Tabela 9

Diagnóstico de correlação linear entre variáveis explicativas

\begin{tabular}{|lcc|}
\hline Variável & Tolerance & VIF \\
\hline Forn $_{n}$ & 0,773 & 1,294 \\
Especif $_{n}$ & 0,800 & 1,250 \\
Freq $_{n}$ & 0,837 & 1,194 \\
Quant $_{n}$ & 0,937 & 1,067 \\
\hline
\end{tabular}

Fonte: Resultados de pesquisa 
Assim, comprova-se que o modelo proposto atende aos pressupostos estatísticos de regressão, sendo ele válido para a previsão das variações dos preços praticados em pregões eletrônicos.

\section{Conclusão}

Os resultados demonstraram que, conforme a teoria dos leilões, o número de participantes tem uma relação forte com a redução dos preços praticados neste tipo de disputa. A justificativa para esta relação é que quanto maior o número de empresas interessadas na venda do objeto em negociação, maior é o acirramento da disputa, e, assim, o órgão público consegue negócios mais lucrativos. Dessa forma, sugere-se que a administração pública crie estratégias para melhorar o sistema de informação para divulgação dos seus processos licitatórios, pois além de conseguir reduzir substancialmente o preço pago nas negociações por causa da maior publicidade, ela cumprirá sua obrigação de gerar maior transparência.

A variável especificidade dos ativos também é determinante na variação dos preços praticados em licitações; porém esta se configura como uma característica do bem contratado, por isso ela é de difícil interpretação e controle. Para conseguir melhores preços, aconselha-se aos órgãos públicos que deem preferência quando existirem produtos similares, menos específicos e que atendam as suas necessidades da mesma forma que um produto com alto grau de especificidade dos ativos.

A variável frequência das transações também se relaciona de maneira positiva com a redução dos preços. Com isso, os órgãos públicos devem buscar a criação de um bom ambiente com as empresas com as quais transaciona e incentivar a participação delas em suas licitações, para assim obter as vantagens que estas empresas proporcionam.

A quantidade comprada também se mostrou determinante na redução dos preços pagos em licitações. Por isso, os órgãos públicos devem se planejar para fazer compras conjuntas e evitar a realização de várias licitações para a compra do mesmo produto, pois assim eles terão maior poder de barganha e poderão exigir diminuições mais substanciais de seus fornecedores.

Por fim, destaca-se que o modelo proposto pode incorporar novas variáveis e pode ser aplicado em outros órgãos públicos do país, o que suscita a iniciativa de outros estudos prospectivos nesta área, servindo, portanto, como sugestão para futuros trabalhos científicos. Também se sugere uma análise qualitativa para conhecer as opiniões e estratégias dos fornecedores quanto 
ao pregão eletrônico.

\section{Referências}

ALVES, J.M.; STADUTO, J.A.R. Análise da estrutura de governança: o caso cédula do produtor rural (CPR). In: WORKSHOP BRASILEIRO DE GESTÃO DE SISTEMAS AGROALIMENTARES, 2., 1999, Ribeirão Preto. Anais... Ribeirão Preto: FEA/USP, 1999. Disponível em: <http://www.fearp.usp.br/egna/arquivo/12.pdf>. Acesso em: 13 dez. 2003.

ARBAGE, A.P. Custos de transação e seu impacto na formação e gestão da cadeia de suprimentos: estudo de caso em estruturas de governança híbridas do sistema agroalimentar no Rio Grande do Sul. 2004. 267 f. Tese (Doutorado em Administração) — Universidade Federal do Rio Grande do Sul, Porto Alegre, 2004.

BATISTA, M.A.C.; MALDONADO, J.M.S.V. O papel do comprador no processo de compras em instituições públicas de ciência e tecnologia em saúde (C\&T/S). Revista de Administração Pública, Rio de Janeiro, v. 42, n. 4, p. 681-699, ago. 2008.

BEUTER, R. European public procurement reform: main innovations in the public sector directive - a preliminary assessment. Eipascope, 2005.

BRÜLHART, M.; TRIONFETTI, F. Public expenditure, international specialization and agglomeration. European Economic Review, v. 48, n. 4, p. 851-881, ago. 2004.

BRUYNE, P.; HERMAN, J.; SCHOUTHEETE, M. Dinâmica da pesquisa em ciências sociais: os polos da prática metodológica. Rio de Janeiro: Francisco Alves, 1991.

CARTER, C.R. et al. Reverse auctions: grounded theory from the buyer and supplier perspective. Logistics and Transportation Review, v. 40, n. 3, p. 183-270, ago. 2004. Transportation Research Part E.

CARTER, C.R.; STEVENS, C.K. Electronic reverse auction configuration: impact on buyer price and perceived buyer opportunism. In: ACADEMY OF MANAGEMENT MEETING, Honolulu, ago. 2005.

CORRAR, L.J.; PAULO, E.; DIAS FILHO, J.M. Análise multivariada. Fipecafi. São Paulo: Atlas, 2007.

COTTARELLI, C. Treasury bill auctions: issues and uses, International Monetary Fund, Monetary and Exchange Affairs Department, mar. 1995.

COX, J.C.; ROBERSON, B.; SMITH, V.L. Theory and behavior of single object auctions. In: SMITH, V.L. (Ed.). Research in experimental economics. Greenwich: JAI 
Press, 1982. v. 2.

DINIZ, E.A.; STOFFEL, J.A.; GOEBEL, M.A. Licitações e compras públicas de alimentos numa perspectiva da nova economia institucional: o caso Toledo (PR). Revista Informe Gepec, v. 8, n. 2, jul./dez. 2004.

DURÃES, M.S.D. Teoria dos leilões: abordagem comparativa com ênfase nos leilões de títulos do Tesouro no Brasil e em outros países. Brasília: Esaf, 1997.

DYER, D.; KAGEL, J.H.; LEVIN, D. Resolving uncertainty about the number of bidders in independent private-value auctions: an experimental analysis. Rand Journal of Economics, v. 20, n. 2, p. 268-279, 1989.

ENGELBRECHT-WIGGANS, R.; KATOK, E. Regret in auctions: theory and evidence. Economic Theory, v. 33, n. 1, p. 81-101, 2007.

FERRO, E.; DADAYAN, L. Can government be a good eBayer? The use of online auctions in the sale of surplus property. In: HAWAII INTERNATIONAL CONFERENCE ON SYSTEM SCIENCES, 39., 2006, Hawaii. Proceedings... Hawaii, 2006.

GIL, A.C. Como elaborar projeto de pesquisa. 4. ed. São Paulo: Atlas, 2002.

HAIR, J.F.; ANDERSON, RE.; TATHAM, R.L.; BLACK, W.C. Análise multivariada de dados. 5 ed. Porto Alegre: Bookman, 2005.

HARSTAD, R.M. Rational participation revolutionizes auction theory. Working Papers, Department of Economics, University of Missouri, 2005.

HYYTINEN, A.; LUNDBERG, S.; TOIVANEN, O. Favoritism in public procurement: evidence from Sweden. Research Institute of the Finnish Economy and Umea, 2006.

JUNIOR, R.J.C.; MACHADO, R.T.M. Acordos contratuais sob a ótica da economia dos custos de transação: o caso de uma agroindústria canavieira no estado de Pernambuco. In: CONGRESSO INTERNACIONAL DE ECONOMIA E GESTÃO DE REDES AGROALIMENTARES, IV. Anais... Ribeirão Preto, 2003.

KLEIN, S. Electronic auctions. International Journal of Electronic Markets, v. 7, n. 4, p. 217-230, dez. 1997.

KLEMPERER, P. Auctions: theory and practice. Princeton University Press, 2004.

LÖSCH, A. Combining quantitative methods and grounded theory for researching e-reverse auctions. Libri, 2006.

,; LAMBERT, J.S. E-reverse auctions revisited: an analysis of their context, buyer-supplier relations, and information behaviors. Journal of Supply Chain Management, v. 1, n. 13, p. 116-131, 2007.

LUCCI, C.R. Custos de transação no ambiente portuário: uma aplicação da nova econo- 
mia institucional para o porto de Santos. In: SEMEAD, VII. Anais... São Paulo, 2004. MAROCO, J. Análise estatística. Lisboa: Sílabo, 2003.

MENEZES, R.A.; SILVA, R.B.; LINHARES, A. Leilões eletrônicos reversos multiatributo: uma abordagem de decisão multicritério aplicada às compras públicas brasileiras. Revista de Administração Contemporânea, Rio de Janeiro, v. 11, n. 3, p. 11-33, 2007.

MILLET, I. et al. Metrics for managing online procurement auctions. Interfaces, 2004.

NORTH, D.C. Custos de transação, instituições e desempenho econômico. Cambridge: University Press, 1994.

NUNES, J.; LUCENA, R.L.; SILVA, O.G. Vantagens e desvantagens do pregão na gestão de compras no setor público: o caso da Funasa (PB). Revista do Serviço Público, v. 3, n. 6, p. 11-45, abr./jun. 2007.

PERES, U. Custos de transação e estrutura de governança no setor público. Revista Brasileira de Gestão de Negócios, v. 9, n. 24, p. 15-30, maio/ago. 2007.

PINTO JÚNIOR, H.Q.; PIRES, M.C.P. Assimetria de informações e problemas regulatórios. Nota Técnica, n. 9, fev. 2000.

PINTO, S.L. A aplicação da tecnologia da informação às compras governamentais na administração federal. Revista Informática Pública, v. 3, n. 4, p. 56-89, 2002.

PREGÃO Eletrônico reduziu custos das compras do governo federal em até $30 \%$ em dois anos. ComprasNet. Disponível em: <www.comprasnet.gov.br/noticias>. Acesso em: 17 fev. 2005.

REILEY, D. L. et al. Pennies from eBay: the determinants of price in online auctions. The Journal of Industrial Economics, v. 45, n. 5, p. 567-596, 2007.

RESNICK, P.; ZECKHAUSER, R. Trust among strangers in internet transactions: empirical analysis of eBay's reputation system. In: The Economics of the Internet and E-Commerce, 2002.

SANTOS , R.T. Coordenação de investimentos e políticas de introdução da concorrência na indústria de gás natural: elementos para análise de casos no Brasil. Dissertação (Mestrado em Economia) — Instituto de Economia, Universidade Federal do Rio de Janeiro, 2001.

SHAWN, P.D.; NATH, P. Reverse auctions for relationship marketers. Industrial Marketing Management, 2005.

SILVA, A.A.; FERREIRA R.T. Pregões eletrônicos realizados pela prefeitura municipal 
de Fortaleza em 2006: um ensaio econométrico. Fortaleza, 2007. Prêmio Sefin de Finanças Municipais.

SMELTZER, L.R.; KARR, A. Electronic reverse auctions: promises, risks and conditions for success. Industrial Marketing Management, 2003.

SOUSA, E.L.L.; AZEVEDO, P.F.; SAES, M.S.M. Competitividade do sistema agroindustrial do milho. Brasília: Trabalho Técnico, 1998.

TEO, T.S.H.; LIN, S.; LAI, K. Adopters and non-adopters of e-procurement in Singapore: an empirical study. Omega, 2008.

VALLE, M.G.; BONACELLI, M.B.M.; FILHO, S.S. Redes de inovação tecnológica: aportes da economia evolucionista e da nova economia institucional. In: CONGRESSO INTERNACIONAL DE ECONOMIA E GESTÃO DE NEGÓCIOS AGROALIMENTARES, 3, 2001. Anais... Ribeirão Preto, 2001.

. Aportes da economia evolucionista e da nova economia institucional na constituição de arranjos institucionais de pesquisa. In: SIMPÓSIO DE GESTÃO DA INOVAÇÃ̃O TECNOLÓGICA, XXII. Anais... Salvador, 2002.

VASCONCELLOS, F. Licitação pública: análise dos aspectos relevantes do pregão. Disponível em: <www.ccj.ufpb.br/primafacie/prima/artigos/n7/licitacao.pdf > . Acesso em: 25 fev. 2008.

VERGARA, S.C. Projetos e relatórios de pesquisa em administração. 3. ed. São Paulo: Atlas, 2005.

WENYAN, H.; BOLÍVAR, A. Online auctions efficiency: a survey of eBay auctions. Alternate track: industrial practice and experience. Beijing, 2008.

WILLIAMSON, O.E. The economics institutions of capitalism. Free Press, 1985.

WILLIAMSON, O.E.; AOKI, M.; GUSTAFSSON, B. The firm as a nexus of treaties. London: Sage Publications, 1990.

WOLFSTETTER, E. Topics in microeconomics: industrial organizations, auctions and incentives. Cambridge: Cambridge University Press, 1999.

ZYLBERSZTAJN, D. Organização ética: um ensaio sobre comportamento e estrutura das organizações. Revista de Administração Contemporânea, Rio de Janeiro, v. 6, n. 2, p. 123-143, maio/ago. 2002. 